\title{
Planejamento tributário e análise dos incentivos fiscais da SUDENE em uma empresa de fruticultura localizada em Mossoró/RN
}

\author{
Francisco Antônio Alves ${ }^{1}$ \\ Geison Calyo Varela de Melo ${ }^{2}$ \\ Ítalo Carlos Soares do Nascimento ${ }^{3}$ \\ Caritsa Scartaty Moreira ${ }^{4}$
}

\begin{abstract}
RESUMO
O Rio Grande do Norte é destaque na fruticultura como o maior produtor e exportador de melão do Brasil, com produção concentrada na região de Mossoró/RN e para se chegar a esse nivel o estado enfrentou uma verdadeira batalha, a começar pela escassez de água e problemas na infraestrutura de portos, aeroporto e rodovias, bem como as questões tributárias. Dessa forma, o objetivo da pesquisa consiste em evidenciar a economia tributária gerada por uma empresa de Fruticultura beneficiada com incentivos fiscais da Superintendência do Desenvolvimento do Nordeste (SUDENE). Para tanto, desenvolveu-se uma pesquisa classificada como descritiva e explicativa, com abordagem qualitativa e documental. Os dados para realizar o estudo de caso foram extraídos de uma Demonstração do Resultado do Exercício (DRE) fornecida pela empresa referente ao exercício 2019, para fundamentar a pesquisa foram baixados arquivos e noticiários da internet sobre a empresa. Diante do resultado, ficou clara a importância do segmento meloeiro para a economia do RN e o incentivo fiscal como uma ferramenta indispensável ao desenvolvimento regional, pois apesar das dificuldades enfrentadas pelo setor, a pesquisa evidenciou a economia tributária gerada pela empresa mediante os incentivos fiscais da SUDENE, reforçando ainda, a importância da parceria entre os órgãos governamentais e as empresas.
\end{abstract}

Palavras-chaves: fruticultura; melão; incentivo fiscal; SUDENE.

\section{Tax planning and analysis of SUDENE's fiscal incentives in a fruitculture company located in Mossoró/RN}

\begin{abstract}
Rio Grande do Norte is highlighted in fruit culture as the largest melon producer and exporter in Brazil, with production concentrated in the region of Mossoró / RN and to reach this level the state faced a real battle, starting with the scarcity of water and problems in the infrastructure of ports, airports and highways, as well as tax issues. Thus, the objective of the research is to highlight the tax savings generated by a Fruit and Vegetable company benefited with tax incentives from the Northeast Development Superintendence (SUDENE). To this end, a research classified as descriptive and explanatory, with a qualitative and documentary approach, was developed. The data to carry out the case study were extracted from a Statement of Income for the Year (DRE) provided by the company for the year 2019, to support the research, files and news were downloaded from the internet about the company. Given the result, it became clear the importance of the melon segment for the economy of RN and the tax incentive as an indispensable tool for regional development, because despite the difficulties faced by the sector, the research showed the tax savings generated by the company through the tax incentives of the SUDENE, further reinforcing the importance of partnership between government agencies and companies.
\end{abstract}

Keywords: fruit growing; melon; tax incentive; SUDENE.

\footnotetext{
1 Especialista em Contabilidade e Planejamento Tributário pela Universidade Federal Rural do Semi-Árido (UFERSA), Endereço: Rua Francisco Mota, no 572 - Bairro Presidente Costa e Silva, Mossoró/RN, CEP: 59625-900, E-mail: francisco4nb@gmail.com

${ }^{2}$ Doutorando em Administração e Controladoria pela Universidade Federal do Ceará (UFC), Professor do curso de Administração da Universidade do Estado do Rio Grande do Norte (UERN), Endereço: BR 405, KM 3, Arizona - Pau dos Ferros/RN, CEP: 59900-000, E-mail: geisoncalyo@ hotmail.com.

${ }^{3}$ Doutorando em Administração e Controladoria pela Universidade Federal do Ceará (UFC), Professor do curso de Ciências Contábeis da Faculdade Católica do Rio Grande do Norte (FCRN), Endereço: Rua Doutor João Marcelino, no 511 - Santo Antônio, Mossoró/RN, CEP: 59611-030, E-mail: ítalocarlos25@gmail.com.

${ }^{4}$ Doutoranda em Ciências Contábeis pela Universidade Federal da Paraíba (UFPB), Endereço: Campus I - Lot. Cidade Universitária, João Pessoa/PB, CEP: 58051-900, E-mail: caritsascarlaty@gmail.com.
} 


\section{INTRODUÇÃO}

A fruticultura é um dos segmentos mais promissores do Brasil, ocupando a $3^{\text {a }}$ posição do ranking mundial em produção de frutas e o $23^{\circ}$ lugar nas exportações, porém, o país só exporta $3 \%$ de toda a fruta produzida, o restante é direcionado para o mercado interno, demonstrando uma disparidade na relação de frutas produzidas e exportadas, mostrando o potencial de crescimento capaz de elevar as receitas das exportações brasileiras (ABRAFRUTAS, 2018).

Através do cultivo de frutas, a região Nordeste está conseguindo sair do cenário de extrema pobreza e abandono provocado pelas secas constantes, nesse quadro, destaca-se a produção de melão que coloca o Rio Grande do Norte como o maior produtor do Brasil, representando $60 \%$ do total produzido (PINHEIRO, 2017).

A fruta começou ser produzida no estado na década de 1980 e teve como pioneira a extinta empresa MAISA, localizada na região de Mossoró-RN, sua primeira exportação foi registrada em 1982, além de ser responsável pelo desenvolvimento regional na redução da pobreza, a empresa abriu o mercado meloeiro, tornando o melão potiguar forte e conhecido em todo o mundo devido a sua alta qualidade em brix (teor de açúcar) e sabor (TRIBUNA DO NORTE, 2011).

Localizado em um setor com predominância de clima semiárido, que tem por característica a baixa incidência de chuvas, mas sobre uma grande bacia hidrográfica subterrânea, as empresas do Rio Grande do Norte conseguiram solucionar o problema de escassez de água através de poços artesianos e tecnologias de irrigação obtidas de Israel (ALVES, 2013).

No entanto, esses não são os únicos problemas dos produtores, a falta de incentivos fiscais e investimento em infraestrutura como: portos, aeroportos e rodovias ou ferrovias para escoar a produção, como também para compra de insumos, representa um dos maiores gargalos do setor. Além do mais, existem diversos problemas fitossanitários decorrentes do ataque de pragas, doenças e plantas daninhas, levando o produtor a adotar medidas de controle nos pomares (LEITE et al., 2016).

Porém, o maior dispêndio monetário está centrado na alta carga tributária que na abordagem da Receita Federal (2017) através de um estudo realizado entre países membros da OCDE (Organização de Cooperação do Desenvolvimento Econômico) na qual o Brasil faz parte, a carga tributária brasileira em 2017 representou 32,43\% do Produto Interno Bruto (PIB).

Nascido na década de 1960, através do art. 34 da lei 3.995/61 e melhorado no art. 18 da lei 4239/63, os incentivos fiscais da SUDENE tem como objetivo reduzir o custo dos produtos através da redução do tributo e assim atrair investimento para a região Nordeste reduzindo a desigualdade social e econômica existente entre as outras regiões do Brasil, de acordo com Costa (2016), apenas em casos realmente especial que é concedido o benefício fiscal, pois a concessão do incentivo reduz o recolhimento de receita do estado.

Dentro desse contexto, surge a seguinte questão de pesquisa: Qual a economia tributária gerada por uma empresa de Fruticultura beneficiada com incentivos fiscais da SUDENE? Dessa forma, para atender a esse questionamento, a pesquisa apresenta o objetivo de evidenciar a economia tributária gerada por uma empresa de Fruticultura beneficiada com incentivos fiscais da SUDENE.

O planejamento tributário é um direito destacado em lei, que permite através do estudo das operações das empresas, buscar nas lacunas existentes nas leis, uma maneira menos onerosa para executar suas operações (FABRETTI, 2007). A elaboração do planejamento tributário é uma forma lícita de reduzir pagamentos com tributos, devendo ser realizado por profissionais qualificados e competentes capazes de promover de forma lícita a redução de custos nas empresas através da redução do tributo, de forma segura e legal sem riscos de prejuízos futuros (LONDERO, 2015). 
Nesse sentido, o estudo justifica-se pela relevante discussão da temática e apesar do Brasil ser o terceiro produtor mundial de frutas e com destaque para a Região Nordeste como uma das principais produtoras, especialmente em cidades interioranas (LEITE et al., 2016), surge a necessidade de incrementar os estudos e as discussões dessa temática, principalmente com a abordagem voltada para o desenvolvimento local em pequenas comunidades de produção.

\section{REVISÃO DE LITERATURA}

\subsection{Planejamento Tributário: principais aspectos e definições}

Na contabilidade encontram-se várias ferramentas capazes de ajudar na redução de custos das empresas, dentre elas, o planejamento tributário se caracteriza como crucial e indispensável permitindo ao empresário através da redução dos tributos aumenta a lucratividade e garantir a sustentabilidade da entidade, tendo em vista que se caracteriza como uma forma lícita de reduzir a carga fiscal (FABRETTI, 2007; OLIVEIRA et al., 2010).

Conforme a Lei $\mathrm{n}^{\circ}$ 5.172/66 (CTN) art. 116, parágrafo único, as autoridades administrativas poderão desconsiderar atos ou negócios jurídicos praticados com a finalidade de evitar a ocorrência do fato gerador ou a natureza dos elementos constitutivos da obrigação, desde que cumpram os procedimentos estabelecidos em lei ordinária.

Com uma complexa e onerosa legislação tributária, o Brasil, exige do empresário bastante cautela na hora da tomada das decisões, Zangirolami (2010) aborda que, para realizar um bom planejamento tributário todas as ações de compras, vendas, devolução, transferência, compensação de tributos, enquadramento da empresa, se a mercadoria adquirida ou vendida enquadra-se em algum tratamento especial como é o caso da substituição, verificar a alíquota do estado de origem, alíquota do estado de destino, como também conhecer juridicamente seus clientes e fornecedores, esses pontos devem ser analisados com bastante cuidado em conformidade com a legislação vigente a fim de evitar surpresas futuras capazes de gerar prejuízos.

A escolha do regime tributário a ser adotado pela empresa é de extrema importância, pois define como será o recolhimento do IRPJ, CSLL, PIS, COFINS que são tributos incidentes em todas as operações das empresas, conforme Caires (2016) o planejamento deve ser elaborado por profissionais especialista no assunto que através do estudo identifique qual a melhor opção entre os regimes de apuração dos tributos, Lucro Real, Presumido ou Simples Nacional, identificando qual é o menos oneroso a ser adotado pela empresa, nesse caso, a empresa em análise é optante do lucro real e será conceituado apenas o regime tributário adotado pela entidade, pois o programa de incentivo fiscal em questão só aceita empresas optantes do lucro real.

\subsection{A Fruticultura e o cultivo de Melão no Rio Grande do Norte}

A Fruticultura irrigada transformou a realidade do povo brasileiro e especialmente do nordestino, pautada como um dos principais produtos da exportação do estado, o melão mudou o cenário, tirando aqueles campos secos e desertos desenhados pela seca e colocou uma tela agradável e verde onde é perceptível a vida, o desenvolvimento e a esperança de dias melhores (OLIVEIRA et al., 2016).

O melão é considerado um dos principais produtos da economia nordestina, de acordo com Salviano et al. (2017) o nordeste brasileiro respondeu em 2013 por $95 \%$ da produção do país, entre os estados produtores o Ceará e o Rio Grande do Norte se destacam, os dois representaram $82,5 \%$ da produção nordestina em 2017, a Tabela 1 a seguir mostra a produção de melão do Brasil no ano de 2017 separadas por região. 
Tabela 1: Quantidade de melão produzida em 2017

\begin{tabular}{cc}
\hline BRASIL E REGIÕES & QUANTIDADE DE MELÃO (Ton.) \\
\hline Brasil & 540.229 \\
Norte & 1.064 \\
Nordeste & 514.276 \\
Sudeste & 363 \\
Sul & 22.432 \\
Centro-Oeste & 2.094 \\
\hline
\end{tabular}

Fonte: IBGE (2018).

Por meio da Tabela 1, no ano de 2017, pode-se inferir que a produção de melão representa relevância e participação na Fruticultura brasileira, presente em todas as regiões do país, com maior destaque e concentração na região Nordeste, seguido pelas regiões Sul e Centro-Oeste, nas regiões Norte e Sudeste, a produção é menor, porém apresenta ainda significância na produção brasileira.

Segundo dados do IBGE (2018), com 338.665 mil toneladas em 2017 e 13.133ha plantadas, o RN é considerado o maior produtor de melão do Brasil e suas lavouras espalharamse por 19 (dezenove) municípios do RN, apresentando concentração de 95\% entre as cidades de: Mossoró (60,68\%), Tibau (15,17\%), Apodi (7,59\%), Baraúna (3,79\%), Ipanguaçu (3,20\%); Governador Dix-sept Rosado (2,29\%), Macau (2,28\%), além de sua importância na geração de receita para o estado, as empresas de melão contribui bastante na criação de novos postos de trabalho, conforme Oliveira et al. (2010) o agronegócio do melão gera em média 28 mil empregos diretos e 54 mil indiretos no RN, tornando-se de grande importância para a economia do estado.

Santos e Santos (2016) destacam que o principal destino do melão produzido no estado é para os países da Europa, entre eles estão: Holanda, Reino Unido, Espanha, Itália, Irlanda e outros mercados que já estão em fase inicial de exploração, como é o caso dos Emirados Árabes e Rússia, porém o mercado estrangeiro é exigente e complicado, para continuar atendê-los, as empresas precisam se ajustar as exigências mercadológicas, investindo em inovações, tecnologia e mão-de-obra qualificada.

Embora o setor de fruticultura seja de grande importância para o estado, os produtores de frutas ainda enfrentam muitos problemas, conforme o Jornal Tribuna do Norte (2015) destaca como principais carências: A falta de incentivos fiscais, problemas logísticos e tarifas mais atrativas, limitam os investimentos, e o escoamento da produção de melão do estado, apesar do RN ser privilegiado pela localização geográfica relacionado a sua proximidade com o continente Europeu, grande parte da fruta produzida no RN é embarcada pelos portos do Ceará.

Além dos problemas apresentados, o segmento ainda enfrenta o alto custo de produção, que de acordo com Brasil et al. (2008) para produzir um hectare de melão amarelo, o empresário desembolsa em média $\mathrm{R} \$ 12.469,76$ e o item com maior significância é o insumo, que representa $57,22 \%$ do custo. É sabido que, quanto maior a produtividade, mais o custo é diluído, com base em 2018 a rentabilidade do melão amarelo produzido no RN aumentou em média $26 \%$, tal fator é atribuído a novas tecnologias inseridas no segmento, atualmente as empresas veem conseguindo deixar seus gastos menos onerosos e seus produtos mais competitivas no mercado (BRASIL, 2019).

Araújo e Campos (2011) destacam que, numa atividade que gera riqueza e comercializa um produto altamente perecível, o papel da logística é fundamental para o sucesso da operação, que é iniciado pela aquisição dos insumos, provenientes de importação ou adquiridas no mercado nacional, com seus principais fornecedores nos estados do sul e sudeste, e fechando 
com a logística externa, que deve ser precisa e ágil desde a pós-colheita da fruta até o cliente final, garantindo a boa qualidade da fruta na mesa do consumidor final.

\subsection{Incentivos Fiscais da SUDENE}

Criada por meio da Lei $n^{\circ} 3.692 / 59$, a Superintendência do Desenvolvimento do Nordeste (SUDENE), teve como seu primeiro diretor, o senhor Celso Furtado, que se subordinava apenas ao Presidente da República, sendo administrativamente autônoma e sediada na cidade do Recife, no Pernambuco e abrangia os estados que compõe a região Nordeste do país até a zona de Minas Gerais, compreendida no Polígono das Secas (BRASIL, 1959).

Conforme Locatel e Lima (2015), o órgão possui como objetivo principal promover o desenvolvimento do Nordeste, tornando a região autossustentável, através de suas atribuições, como: estudar e propor diretrizes de desenvolvimento; supervisionar e controlar a elaboração projetos; executar diretamente ou mediante convênio; coordenar, desde que tais projetos representem importância econômica para a região. Apesar de sua importância para economia, no ano de 1999, a SUDENE perdeu força e foi extinta, retornando em 2002, com nome de Agência do Desenvolvimento do Nordeste (ADENE) e somente em 2007, através da Lei $n^{\circ}$ 125/07, o órgão reassumiu seu antigo nome (NEVES, 2017).

Os incentivos fiscais para o desenvolvimento do Nordeste foram instituídos através da Lei $\mathrm{n}^{\mathrm{o}} 3.995 / 61$, concomitante a aprovação do primeiro plano diretor, que tinha como prioridade inicial a realização de obras e serviços. O Ministério de Estado da Integração Nacional, buscando simplificar a localização dos usuários em relação à base legal dos incentivos, publicou a Portaria $\mathrm{n}^{\circ} 283 / 2013$ que regula todos os incentivos fiscais administrados pela SUDENE, inclusive o benefício que reduz em $75 \%$ o IRPJ e adicionais não restituíveis.

Atualmente, a MP 2.199-14/01 altera a legislação do Imposto de Renda normatizando o programa do governo para o desenvolvimento do Norte e Nordeste, no qual disponibiliza para as empresas com projetos de investimentos considerados como prioritários para o desenvolvimento da região Nordeste, protocolizados e aprovados até dezembro de 2018 os seguintes incentivos.

Quadro 1: Incentivos fiscais concedidos pela SUDENE

\begin{tabular}{|c|l|}
\hline \multirow{4}{*}{$\begin{array}{c}\text { Principais } \\
\text { incentivos }\end{array}$} & $\begin{array}{l}\text { Redução de 75\% sobre o Imposto de Renda da Pessoa Jurídica (IRPJ) e adicionais não restituíveis } \\
\text { calculados sobre o lucro de exploração; }\end{array}$ \\
\cline { 2 - 3 } & $\begin{array}{l}\text { Isenção do IRPJ e adicional não restituível calculado sobre o lucro de exploração, para empresas } \\
\text { fabricantes de máquinas e equipamentos e instrumentos voltados à inclusão digital; }\end{array}$ \\
\cline { 2 - 3 } & Depreciação acelerada incentivada (extinto em 2019); \\
\cline { 2 - 3 } & Desconto do PIS e COFINS na compra de máquinas e equipamentos (Extinto em 2019); \\
\cline { 2 - 3 } & Depósito para reinvestimento de 30\% do IRPJ Devido. \\
\hline
\end{tabular}

Fonte: Elaborado pelos autores (2020).

Pautados no art. $2^{\circ}$ da Lei $n^{\circ} 125 / 07$, para aderir aos incentivos fiscais, destacados no Quadro 1, a empresa deve ter projeto de investimento dentro do perímetro de cobertura da SUDENE, que corresponde a todos os estados da região Nordeste, o Norte do Espirito Santo e os municípios localizados no Vale do Jequitinhonha estado de Minas Gerais; deve ser optante em recolher o IRPJ na modalidade lucro real, pois o benefício é dado sobre o lucro de exploração e os investimentos classificados como: Implantação, modernização, ampliação (total e parcial) ou diversificação, apresentando importância econômica para o desenvolvimento da região.

O Decreto de Lei $\mathrm{n}^{\circ} 4.213 / 03$, define em seu art. $2^{\circ}$ incisos de I a VI, os setores da economia considerados como prioritários ao benefício fiscal, amparados pela MP 2199/02 e expostos no Quadro 2. 
Quadro 2: Setores da economia com prioridade para o recebimento de incentivos fiscais

\begin{tabular}{|c|c|}
\hline SETORES & DEFINIÇÃO \\
\hline Infraestrutura & $\begin{array}{l}\text { Engloba energia, gás, telecomunicação, transportes, esgoto sanitário e } \\
\text { abastecimento de água; }\end{array}$ \\
\hline Turismo & Envolve hotéis, centro de convecção e outros projetos integrados; \\
\hline Agroindústria & Reúne a agricultura irrigada, projetos de irrigação, piscicultura e aquicultura; \\
\hline $\begin{array}{l}\text { Agricultura Irrigada e } \\
\text { Fruticultura }\end{array}$ & $\begin{array}{l}\text { Objetiva a produção de alimentos e matérias-primas voltadas para o mercado } \\
\text { interno e externo; }\end{array}$ \\
\hline Indústria de transformação & $\begin{array}{l}\text { Compreendem as indústrias têxtis e vestuários, como também as indústrias } \\
\text { químicas farmacêuticas. }\end{array}$ \\
\hline
\end{tabular}

Fonte: Elaborado pelos autores (2020).

De acordo com o Quadro 2 e mesmo que apresente apenas os prioritários, os setores econômicos que podem receber os incentivos fiscais são diversos, abrangem uma enorme variedade de atividades econômicas que apresentam relevância para a economia brasileira e não engloba apenas setores ligados à agropecuária e afins, mas também setores que vão desde o turismo, a infraestrutura e indústrias. Para garantir os benefícios fiscais concedidos pela SUDENE, as empresas devem proceder com algumas obrigatoriedades, conforme Portaria $n^{\circ}$ 283/13 e disposto no Quadro 3 a seguir.

Quadro 3: Obrigatoriedades por parte das empresas

\begin{tabular}{|c|c|}
\hline \multirow{6}{*}{$\begin{array}{l}\text { Obrigatoriedades } \\
\text { das Empresas }\end{array}$} & $\begin{array}{l}\text { No final de cada exercício, deve ser enviado para SUDENE as declarações de rendimentos, } \\
\text { indicando o valor correspondente à redução de } 75 \% \text { do IRPJ e adicionais não restituíveis. }\end{array}$ \\
\hline & $\begin{array}{l}\text { A economia tributária deve ser aplicada em atividades diretamente ligadas a produção } \\
\text { beneficiada da empresa. }\end{array}$ \\
\hline & $\begin{array}{l}\text { O valor correspondente à econômica gerada pelo benefício em hipótese alguma deve ser } \\
\text { distribuído como lucros aos sócios, devendo no final do exercício constitui reserva de } \\
\text { incentivos fiscal de acordo com o regime de competência. }\end{array}$ \\
\hline & $\begin{array}{l}\text { A economia tributária gerada pelo incentivo fiscal SUDENE, só pode ser utilizado para } \\
\text { aumento de capital da empresa devendo ser informado à receita e a SUDENE no prazo de } 60 \\
\text { dias a cada operação de aumento de capital, junto ao comunicado deve ser entregue cópia das } \\
\text { demonstrações contábeis destacando as operações. }\end{array}$ \\
\hline & $\begin{array}{l}\text { Para aderir aos incentivos fiscais SUDENE, deve ser elaborado um projeto conforme o } \\
\text { Manual de instrução para elaboração de pleitos, disponibilizado no site da SUDENE e, de } \\
\text { acordo com o regulamento dado pela Portaria } n^{0} 283 / 07 \text {, do Ministério da Integração } \\
\text { Nacional. }\end{array}$ \\
\hline & $\begin{array}{l}\text { O não cumprimento dos requisitos desses artigos acarretará na perda do incentivo e na } \\
\text { obrigatoriedade de recolhimento do imposto integral. }\end{array}$ \\
\hline
\end{tabular}

Fonte: Elaborado pelos autores (2020).

Como disposto no Quadro 3, para assegurar os incentivos fiscais da SUDENE, as empresas que elaborar um projeto conforme o Manual de Instrução para Elaboração de Pleitos, disponibilizado no site da SUDENE e de acordo com o regulamento dado pela portaria 283/07 do Ministério da integração, devem ainda cumprir com uma série de obrigações, que vão desde a divulgação de dados das empresas (relacionados a transparência), até mesmo a aplicabilidade dos recursos oriundos da economia tributária. As empresas necessitam se atentar aos requisitos determinados, pois caso não sejam cumpridos, pode implicar em consequências, como penalidades e perda dos incentivos concedidos. 


\subsection{Estudos correlatos sobre a temática}

A seguir, procedeu-se com um levantamento bibliográfico com o intuito de identificar estudos com arcabouço semelhante à presente pesquisa e estão dispostos no Quadro 4, os principais já desenvolvidos relacionados a temática em questão.

\begin{tabular}{|c|c|c|c|}
\hline \multicolumn{4}{|c|}{ Quadro 4: Estudos anteriores } \\
\hline AUTOR/ANO & TÍTULO & OBJETIVO & RESULTADOS \\
\hline $\begin{array}{l}\text { Brasil et al. } \\
(2008)\end{array}$ & $\begin{array}{l}\text { Custos do cultivo do } \\
\text { melão amarelo na safra } \\
\text { 2006/2007: um estudo } \\
\text { de caso na empresa } \\
\text { Santa Júlia Agro } \\
\text { Comercial Exportadora } \\
\text { de Frutas Tropicais }\end{array}$ & $\begin{array}{l}\text { Mensurar os custos de } \\
\text { produção do melão } \\
\text { amarelo, tanto pelo modelo } \\
\text { de custo operacional } \\
\text { desenvolvido pelo Instituto } \\
\text { de Economia Agrária, } \\
\text { como, pelo sistema de } \\
\text { custeamento ABC }\end{array}$ & $\begin{array}{l}\text { O método do IEA demonstra que o } \\
\text { item mais significante do processo } \\
\text { são os insumos, que representam } \\
57,22 \% \text { do gasto total. O sistema } \\
\text { ABC, nota-se que os processos que } \\
\text { mais consumiram recursos foram } \\
\text { Tratos Culturais, com } 45,28 \% \text {, e } \\
\text { Proteção de Plantas, com } 30,68 \% \text {. }\end{array}$ \\
\hline $\begin{array}{l}\text { Zangirolami } \\
(2010)\end{array}$ & $\begin{array}{l}\text { Planejamento } \\
\text { Tributário: Estudo } \\
\text { realizado em uma } \\
\text { empresa que atua no } \\
\text { ramo de comercio } \\
\text { varejista de } \\
\text { combustíveis }\end{array}$ & $\begin{array}{l}\text { Um estudo sobre a melhor } \\
\text { alternativa de } \\
\text { enquadramento e } \\
\text { pagamento de tributos } \\
\text { federais de uma empresa } \\
\text { que atua no comércio } \\
\text { varejista de combustíveis }\end{array}$ & $\begin{array}{l}\text { Através de um planejamento } \\
\text { tributário, reduzir o pagamento de } \\
\text { impostos, sem infringir a } \\
\text { legislação. Optando o regime } \\
\text { tributário correto, resulta na } \\
\text { própria manutenção e permanência } \\
\text { da empresa no mercado. }\end{array}$ \\
\hline Londero (2015) & $\begin{array}{l}\text { Planejamento Tributário } \\
\text { como ferramenta de } \\
\text { estratégia de negócios } \\
\text { competitiva para Micro } \\
\text { e pequenas empresas }\end{array}$ & $\begin{array}{l}\text { Demonstrar que a } \\
\text { elaboração de } \\
\text { Planejamento Tributário, } \\
\text { por micro e pequenas } \\
\text { empresas pode leva-las a } \\
\text { obter uma vantagem } \\
\text { competitiva, frente aos } \\
\text { seus concorrentes, }\end{array}$ & $\begin{array}{l}\text { Evidenciou-se que a elaboração de } \\
\text { planejamento tributário por micro e } \\
\text { pequenas empresas, pode } \\
\text { transforma-se em uma vantagem } \\
\text { frente a seus concorrentes. }\end{array}$ \\
\hline $\begin{array}{l}\text { Santos e Santos } \\
(2016)\end{array}$ & $\begin{array}{l}\text { Estudo da } \\
\text { competitividade das } \\
\text { exportações de melão } \\
\text { entre os estados do } \\
\text { Ceará e Rio Grande do } \\
\text { Norte entre } 1997 \text { e } 2014\end{array}$ & $\begin{array}{l}\text { Analisar o grau de } \\
\text { competitividade da } \\
\text { produção de melão entre os } \\
\text { dois estados, destacando } \\
\text { também a importância do } \\
\text { melão para a econômica } \\
\text { brasileira. }\end{array}$ & $\begin{array}{l}\text { Nota-se que mesmo com a } \\
\text { diferença em termos absolutos } \\
\text { o segmento de melões é mais } \\
\text { dinâmico e representativo no } \\
\text { estado potiguar, merecendo } \\
\text { destaque dentro da expansão do } \\
\text { agronegócio brasileiro }\end{array}$ \\
\hline $\begin{array}{l}\text { Locatel e Lima } \\
\text { (2016) }\end{array}$ & $\begin{array}{l}\text { Territórios rurais e } \\
\text { reestruturação produtiva } \\
\text { do capital do Rio } \\
\text { Grande do Norte }\end{array}$ & $\begin{array}{l}\text { Analisar o processo } \\
\text { contraditório da } \\
\text { reestruturação agrícola no } \\
\text { estado do Rio Grande do } \\
\text { Norte }\end{array}$ & $\begin{array}{l}\text { A reestruturação agrícola no campo } \\
\text { potiguar, nas últimas décadas é } \\
\text { perpassado por um conjunto de } \\
\text { processos globais relacionados à } \\
\text { acumulação do capital, que reflete } \\
\text { na perda da capacidade de decisão } \\
\text { local e no aumento das } \\
\text { desigualdades internas, com o } \\
\text { aumento da densidade técnica em } \\
\text { alguns pontos do território }\end{array}$ \\
\hline
\end{tabular}

Fonte: Elaborado pelos autores (2020).

Conforme o Quadro 4 é possível perceber uma evolução na pesquisa científica nessa área, mesmo que os estudos ainda se encontram escassos, o que é preocupante, tendo em vista que a fruticultura e, mais especificamente, a produção de melão apresentam grande representatividade na economia brasileira, na região nordeste, com destaque para o estado do RN, o que reforça a necessidade da realização desse estudo com contribuições relevantes para a área. 


\section{METODOLOGIA}

Este estudo tem como objetivo evidenciar a economia tributária gerada por uma empresa de fruticultura beneficiada com incentivos fiscais da SUDENE. Foi necessário utilizar abordagens sobre os mais variados assuntos como planejamento tributário, cultivo do melão e sua importância para o RN, identificando a deficiência da infraestrutura, a falta de equipamentos necessário nos portos, incentivos fiscais da SUDENE e sua aplicação no setor meloeiro.

A pesquisa caracteriza-se como descritiva, explicativa, qualitativa e documental. De acordo com Gil (2007) as pesquisas descritivas buscam descrever as características de uma determinada população ou fenômeno estudado, e as pesquisas explicativas são do tipo que mais examinam o entendimento da realidade, uma vez que explica a razão dos acontecimentos.

O estudo utiliza-se de uma abordagem qualitativa por envolver uma interpretação do mundo e por estudar as coisas em seus cenários naturais, tentando entender os fenômenos em termos dos significados que as pessoas a eles conferem, ainda nesse tipo de abordagem, não há presença de métodos e técnicas estatísticas para se chegar aos resultados (DENZIN; LINCOLN, 2006).

A amostra da pesquisa compreende uma empresa produtora de melão, localizada na cidade de Mossoró-RN, considerada área de prioridade para os benefícios da SUDENE e usufrui dos benefícios, pois, atende aos pré-requisitos exigidos no regulamento, por estar enquadrada como empresa de fruticultura irrigada e atender a outros requisitos já comentados anteriormente.

Foram analisados documentos disponibilizados pela empresa, como a Demonstração do Resultado do Exercício (DRE) do período de 2019 e outros documentos que serviram de suporte, por isso a pesquisa também é do tipo documental, pois foi fornecido um material confiável e verificou-se a confiabilidade e fidelidade dos documentos consultados para não comprometer a pesquisa realizada (PRODANOV; FREITAS, 2013).

Como mecanismo de tratamento dos dados, foi realizada a técnica de análise de conteúdo, que conforme Bardin (2011) designa um conjunto de técnicas de análise dos materiais disponíveis, visando obter indicadores (quantitativos ou não) que permitam a inferência de conhecimentos relativos às condições de produção/recepção (variáveis inferidas) destes materiais. Assim, a escolha dessa técnica se justifica pela sua aplicabilidade de análise no conteúdo presente nos documentos disponibilizados pela empresa estudada e analisada nessa pesquisa.

\section{RESULTADOS E DISCUSSÃO}

Com base nas informações extraídas da DRE, fornecida pela empesa, no período correspondente ao ano calendário de 2019, e por meio da mesma, é possível evidenciar a economia tributária gerada pela empresa beneficiada com os incentivos fiscais concedidos pela SUDENE.

A DRE é uma demonstração contábil obrigatória às empresas optantes do lucro real, instituída através do art. 187 da Lei 6.404/76, na qual apresenta de forma vertical todas as operações das empresas correspondentes a um determinado período, Segundo Ayres (2012) a demonstração do resultado do exercício é dinâmica que sintetiza as operações que deram origem as receitas e despesas de um determinado período apurado no regime de competência, em seu conteúdo, a DRE confronta as receitas, custos e despesas para então chegar ao lucro contábil do exercício indispensável para identificar a base do IRPJ e CSLL.

As empresas que usufruem de incentivos fiscais identificam dois resultados: o lucro real e o lucro de exploração, para chegar à base de cálculo do IRPJ do lucro de exploração é necessário identificar o percentual de receita representado pela atividade incentivada da empresa, conforme art. 62, inciso III da IN SRF 267/2002 aplica-se sobre o total do lucro de exploração o 
percentual obtido sobre o total das receitas de cada atividade incentivada do mesmo período, é uma informação indispensável, pois, só através dela é possível chegar à base de cálculo do IRPJ.

Os dados contidos na DRE disponibilizada pela empresa, referente ao ano calendário 2019, com recolhimento anual calculado por antecipação ou substituição, evidenciou, dentro do grupo de receitas os valores percentuais representados por cada atividade da empresa, informação indispensável para chegar à base de cálculo do IRPJ no lucro de exploração, conforme Tabela 2.

Tabela 2: Receitas (DRE)

\begin{tabular}{ccc}
\hline CONTAS & VALOR $(\mathbf{R} \$)$ & PERCENTUAL \\
\hline Receita Bruta & $55.988 .305,44$ & $100 \%$ \\
Receita Incentivada & $55.741 .940,16$ & $99,55 \%$ \\
Receita Tributada & $246.365,28$ & $0,45 \%$ \\
\hline
\end{tabular}

Fonte: Elaborada pelos autores (2020).

Acima, identificou-se o valor da receita bruta, bem como o percentual representado por cada receita, em seguida apresentou-se o valor correspondente à atividade incentivada que é de $99,55 \%$ da receita bruta, e a parte com tributação normal, que representa $0,45 \%$ do total, todas as receitas devem ser identificadas e escrituradas de acordo com a legislação vigente, o percentual de cada, será utilizada posteriormente no momento da definição da parcela do lucro de exploração correspondente ao lucro incentivado.

Para dar continuidade ao cálculo é necessário chegar ao o lucro de exploração com os ajustes previstos na legislação, antes das provisões do Imposto de Renda de Pessoa Jurídica (IRPJ), observando que as compensações de prejuízos anteriores não entram nos ajustes da base de cálculo IRPJ do lucro de exploração, em contra partida adiciona-se o valor da Contribuição Social sobre o Lucro Líquido (CSLL), conforme os dados apresentados na Tabela 3 a seguir.

Tabela 3: Ajuste ao Lucro de Exploração

\begin{tabular}{cc}
\hline LUCRO DE EXPLORAÇÃO & VALORES \\
\hline Lucro líquido & $7.518 .838,88$ \\
Adições + CSLL & $795.300,12$ \\
Exclusões & $(3.667 .364,88)$ \\
Base de cálculo IRPJ & $4.646 .774,12$ \\
\hline
\end{tabular}

Fonte: Elaborada pelos autores (2020).

Pelos dados apresentados, o lucro líquido do período sofreu os ajustes necessários para chegar ao lucro tributado pelo IRPJ, a base de cálculo do lucro de exploração que será usado para apurar o IRPJ é de: R \$ 4.646.774,12, começando a apuração do imposto pelo lucro incentivado.

A partir da Tabela 4 foi usado os percentuais de receitas obtidos na Tabela 2, aplicando-se sobre a base de cálculo do IRPJ no lucro de exploração identificado na tabela anterior o percentual correspondente à receita da atividade incentivada da empresa apontado na tabela 2(99,55\%), na sequência aplicamos a alíquota de 15\% (IRPJ) e 10\% correspondente ao adicional do IRPJ (parcela que excedeu R 240.000 por ano) e para finalizar após o cálculo do IRPJ aplicamos a redução de $75 \%$ sobre o IRPJ e o Adicional chegando ao IRPJ bruto de R\$ $1.132 .573,91$ e devido que e reduzido para: $283.143,48$.

Tabela 4: Lucro incentivado

\begin{tabular}{lcccc}
\hline \multirow{2}{*}{ CONTAS } & PERCENTUAL & IRPJ/ & REDUÇ̃̃O & IRPJ \\
& $99,55 \%$ & ADICIONAL & $75 \%$ & DEVIDO \\
\hline
\end{tabular}




\begin{tabular}{ccccc}
\hline $\begin{array}{c}\text { Lucro de exploração do IRPJ (100\%) } \\
\text { Lucro incentivado }\end{array}$ & 4.646 .774 .12 & & & \\
Adicional (4.646.774.12-240000) & 4.625 .863 .64 & $693.879,55$ & $520.409,66$ & $173.469,89$ \\
\hline TOTAL & 4.386 .943 .64 & $438.694,36$ & $329.020,77$ & $109.673,59$ \\
\hline
\end{tabular}

Fonte: Elaborada pelos autores (2020).

A redução de $75 \%$ do IRPJ não pode ser reconhecida como lucro, não podendo ser distribuído aos sócios, deve ser lançado na conta do PL como reserva de incentivo fiscal, de acordo com regulamento deve ser reinvestido na atividade incentivada da empresa ou como absorção de prejuízos.

A Tabela 5 a seguir refere-se à parcela do lucro que sofreu tributação normal de acordo com a legislação vigente, como a empresa em análise tem como atividade principal a produção de melão quase $100 \%$ de sua receita é proveniente da venda de melão, em certas ocasiões a empresa pode auferiu outras receitas, como a venda de um ativo, um serviço prestado entre outras.

Tabela 5: Lucro tributação normal

\begin{tabular}{ccccc}
\hline CONTAS & $\begin{array}{c}\text { PERCENTUAL } \\
\mathbf{0 , 4 4 5 \%}\end{array}$ & $\begin{array}{c}\text { IRPJ/ } \\
\text { ADICIONAL }\end{array}$ & $\begin{array}{c}\text { REDUÇÃO } \\
\mathbf{7 5 \%}\end{array}$ & $\begin{array}{c}\text { IRPJ } \\
\text { DEVIDO }\end{array}$ \\
\hline Lucro de exploração do IRPJ (100\%) & $4.646 .774,12$ & & & \\
Lucro normal & $20.678,14$ & $3.101,72$ & & $3.101,72$ \\
Adicional (4.646.774.12-240000) & $19.521,90$ & $1.952,19$ & & $1.952,19$ \\
\hline TOTAL & & $\mathbf{5 . 0 5 3 , 9 1}$ & $\mathbf{0 , 0 0}$ & $\mathbf{5 . 0 5 3 , 1 9}$ \\
\hline
\end{tabular}

Fonte: Elaborada pelos autores (2020).

Para finalizar, a Tabela 6 apresenta a apuração dos dados, onde está destacado a soma do imposto de renda total do período mais o adicional de $10 \%$, em seguida temos o valor da redução, o imposto de renda devido e a econômica tributária gerada pelo incentivo, com uma

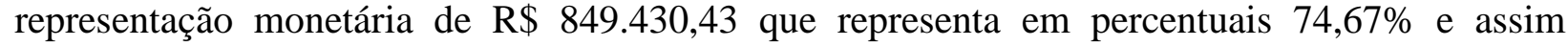
respondendo o problema da pesquisa.

Tabela 6: Resultado

\begin{tabular}{cc}
\hline RESULTADOS & VALORES \\
\hline Imposto de renda total (15\%) & $696.981,27$ \\
Adicional $(10 \%)$ & $440.646,55$ \\
Total bruto do IRPJ + Adiconal & $1.137 .627,82$ \\
Redução de $75 \%$ & $849.430,43$ \\
Valor devido IRPJ & $288.197,39$ \\
Economia gerada pelo incentivo & $74,67 \%$ \\
\hline
\end{tabular}

Fonte: Elaborada pelos autores (2020).

Durante a execução da pesquisa, de acordo com o material utilizado para análise e comprovação teórica que dá materialidade ao estudo de caso, evidenciou-se a economia tributária gerada pela empresa produtora de melão localizada na cidade de Mossoró-RN que aderiu ao incentivo fiscal da SUDENE.

As empresas de melão, localizadas no estado do RN, são responsáveis pela criação de 24 mil empregos diretos e 54 indiretos e são as maiores produtoras do produto do Brasil, o melão 
é um dos principais produtos da pauta de exportação do RN tanto no âmbito econômico como no social na geração de empregos e renda.

Apesar de se apresentar como um segmento importante para o Brasil, o setor ainda tem muitas carências, destacando a falta incentivos fiscais que apesar de já existe segundo os produtores não é suficiente e investimentos em infraestrutura, considerado como um dos maiores gargalos para o setor.

O resultado da pesquisa está de acordo com o estudo apresentado por Santos et al. (2017), que aponta a economia tributária gerada em uma indústria de embarcações que usufrui dos incentivos fiscais por parte da Superintendência para o Desenvolvimento da Amazônia (SUDAM), destacando a importância do incentivo fiscal para desenvolvimento economia da região Norte do Brasil.

Já a pesquisa de Costa (2016) faz abordagens sobre dois períodos de existência da SUDENE, o da sua criação em 1959 com o objetivo de desenvolver a região Nordeste através de investimentos em setores específicos da economia e tinha autonomia de Ministério, respondendo diretamente ao chefe do executivo; e o período atual, que tem como propósito manter os investimentos na região Nordeste, atualmente faz parte do Ministério do Desenvolvimento Regional (MDR) e enfrenta dificuldades na liberação de recursos para exercer suas obrigações.

\section{CONSIDERAÇÕES FINAIS}

Esse estudo tem como objetivo evidenciar a economia tributária gerada em uma empresa produtora de melão, que aderiu ao incentivo fiscal administrado pela SUDENE que é um dos principais órgãos responsáveis pelas diretrizes e metas no que diz respeito às políticas de desenvolvimento regional aplicadas no Nordeste.

Durante a pesquisa foi identificado os pioneiros na produção da fruta na região, tal feito realizada pela extinta empresa MAISA localizada as margens da BR 304 no município de Mossoró, que após enfrentar várias crises financeiras fechou, porém deixou o melão conhecido em todo o mundo devido suas exportações e alta qualidade, além de mão de obra qualificada para os próximos investidores, atualmente o estado é o maior produtor da fruta no Brasil, contribuindo de forma significante para geração de emprego e renda na região.

Por outro lado, apesar de representar um dos segmentos mais importantes para o Rio Grande do Norte, ainda existem bastantes obstáculos, a começar pela falta de investimento em infraestrutura de portos para escoar a produção, outro ponto é alto custo de produção, que graças a aquisição de novas tecnologias e planejamentos tributários, nesse caso a adesão ao incentivo fiscal SUDENE, conseguiu reduzir os custos e tornar os produtos competitivos no mercado interno e externo, assim manter os investimentos na região como também atrair novos investimentos, garantindo emprego renda.

Nos resultados da pesquisa, que evidenciou a economia tributária gerada pela empresa produtora de melão e confirmou a redução da carga tributária, ficou clara a importância do incentivo fiscal para a empresa, como também a importância dessa empresa para a sociedade, reforçando a hipótese que o crescimento econômico e social de uma determinada região, depende da parceria entre o governo e os empresários.

O presente estudo servirá como fonte de pesquisa para profissionais e alunos da área de contabilidade, direito tributário e administração, como também gestores de empresas, pois, além de destacar o melão como principal produto da economia potiguar e sua importância para o desenvolvimento da região, apresenta os incentivos fiscais para o desenvolvimento regional administrado pela SUDENE frente a complexa legislação brasileira.

A limitação dessa pesquisa deu-se pela dificuldade de encontrar uma empresa que operasse com o incentivo fiscal e que disponibilizar informações de extrema importância e sigilo, indispensáveis para chegar ao objetivo da pesquisa, tendo que recorrer aos amigos mais próximos 
para conseguir, outra dificuldade foi pela peculiaridade do trabalho, trabalho que abordo o estudo de caso prático da redução foi muito difícil, com essas características encontrei apenas um.

É indiscutível a importância dos incentivos fiscais SUDENE, porém percebe-se que muitos empresários ainda não usam esse direito como redutor de custos, devido à falta de conhecimento ou até mesmo medo da burocracia necessária para a adesão, esse artigo pode servi como base para as empresas que querem pleitear o incentivo e não conhece sobre o assunto, pois aborda um caso prático e evidencia uma economia tributária real do setor de fruticultura irrigada, seria interessante a produção de outros casos práticos em seguimento diferentes e outros tipos de incentivo tipo deposito para reinvestimento.

\section{REFERÊNCIAS}

ABRAFRUTAS - Associação Brasileira dos Produtos Exportadores de Frutas e Derivados. Brasil é o terceiro maior produtor de frutas do mundo. Brasília/DF, 11 de fevereiro de 2019. Disponível em: $<$ https://abrafrutas.org/2019/03/07/brasil-e-o-terceiro-maior-produtor-de-frutas-do-mundo-dizabrafrutas/>. Acesso em: 30 abr. 2020.

ALMEIDA, A. H. P.; SAMPAIO. R. F.; COSTA, W. P. L. B.; FELIX JÚNIOR, L. A.; SILVA. J. D.; SILVA, S. L. P. Regime aduaneiro especial de Drawback como redutor de custo no setor de fruticultura. In: Congresso Brasileiro de Custos, 21., 2018, Vitória. Anais... Vitória: ABC, 2018.

ALVES, A. P. Convivência com o semiárido brasileiro. In: CONTI, I. L.; SCHROEDER, E. D. (org.). Estratégias de Convivência com o Semiárido Brasileiro: Textos e Artigos de Alunos(as) Participantes. Brasília: Editora IABS, 2013. p. 35-44. Disponível em: <

http://plataforma.redesan.ufrgs.br/biblioteca/pdf_bib.php?COD_ARQUIVO=17908>. Acesso em: 15 maio 2020.

ARAÚJO, V. F. S.; CAMPOS, F. C. A Cadeia logística do melão produzido no agro polo fruticultor Mossoró/Assú. Revista Econômica do Nordeste. v. 42, n. 3, jul./set., 2011.

AYRES, C. F. Z. A convergência da contábil brasileira e a adoção da harmonização contábil no setor elétrico. 2012. 110 f. Monografia (Graduação em Ciências Contábeis) - Departamento de Ciências Administrativas, Contábeis, Econômicas e da Comunicação, Universidade Regional do Noroeste do Estado do Rio Grande do Sul, Rio Grande do Sul, 2012.

BARDIN, L. Análise de conteúdo. São Paulo: Edições 70, 2011.

BRASIL, M. A. S.; OLIVEIRA, K. C.; ARAÚJO NETO, P. L.; VASCONCELOS, A. F. Custos do cultivo do melão amarelo na safra 2006/2007: um estudo de caso na empresa Santa Júlia Agro Comercial Exportadora de Frutas Tropicais Ltda. Custos e @ gronegócio online. v. 4, n. 1, jan./abr., 2008.

BRASIL. Constituição da República Federativa do Brasil (1988). Disponível em: <https://www2.senado.leg.br/bdsf/bitstream/handle/id/518231/CF88_Livro_EC91_2016.pdf〉. Acesso em: 13 mai. 2020.

BRASIL. Lei no 5.172 de 25 de outubro de 1966 (CTN). Dispõe sobre o Sistema Tributário Nacional e institui normas gerais de direito tributário aplicáveis à União, Estados e Municípios. Disponível em: <http://www.planalto.gov.br/ccivil_03/leis/15172.htm>. Acesso em: 25 jun. 2020.

BRASIL. Decreto n 9.580 de 22 de novembro de 2018 (RIR 2018), artigos 259 e 626. Regulamenta a tributação, a fiscalização, a arrecadação e a administração do Imposto sobre a Renda e Proventos de Qualquer Natureza. Disponível em: <http://www.planalto.gov.br/ccivil_03/_ato20152018/2018/decreto/D9580.htm>. Acesso em: 28 mai. 2020. 
BRASIL. Lei ${ }^{\circ} 3.995$ de 14 de dezembro de 1961. Aprova o Plano Diretor da SUDENE, para o ano de 1961, e dá outras providências. Disponível em: <http://www.planalto.gov.br/ccivil_03/leis/19501969/L3692.htm>. Acesso em: 25 mai. 2020.

BRASIL. Lei $\mathrm{n}^{\circ} 3.692$ de 15 de dezembro de 1959. Institui a Superintendência do Desenvolvimento do Nordeste. Disponível em: <http://www.planalto.gov.br/ccivil_03/leis/1950-1969/L3692.htm>. Acesso em: 16 jan. 2020.

BRASIL. MP n ${ }^{\circ} 2.199-14$ de 24 de agosto de 2001. Altera a legislação do imposto sobre a renda no que se refere aos incentivos fiscais de isenção e de redução. Disponível em: <http://www.planalto.gov.br/ccivil_03/MPV/2199-14.htm>. Acesso em: 04 fev. 2020.

BRASIL. Lei $n^{\circ} 125$ de 03 de janeiro de 2007. Institui, na forma do art. 43 da Constituição Federal, a Superintendência do Desenvolvimento do Nordeste - SUDENE. Disponível em: 〈http://www.planalto.gov.br/ccivil 03/leis/lcp/Lcp125.htm〉. Acesso em: 27 jun. 2020.

BRASIL. Decreto $n^{\circ} 4.213$ de abr.2002. Define os setores da economia prioritários para o desenvolvimento regional, nas áreas de atuação da extinta SUDENE. Disponível em: <http://www.planalto.gov.br/ccivil_03/decreto/2002/D4213.htm>. Acesso em: 20 mar. 2020.

BRASIL. Portaria MI n 283 de 04 de julho de 2013. Regulamento dos incentivos fiscais para desenvolvimento regional, administrados pela SUDAM e SUDENE. Disponível em: <http://mi.gov.br/documents/1842527/3718917/PORTARIA+N\%C2\%BA+283+DE+4+DE+JULHO+DE +2013.pdf/f14dea50-9e71-4b13-aef0-e20f354eaa58>. Acesso em: 26 jun. 2020.

CAIRES, L. S.; GAVIOLA, T. F. J. Planejamento tributário como ferramenta estratégica. 2016.78 f. Monografia (Graduação em Ciências Contábeis) - Centro Universitário Católico Salesiano Auxilium, UniSALESIANO, São Paulo, 2016.

COSTA, M. R. O Estado e a SUDENE: trajetória do planejamento regional no Brasil. 2016. 216 f. Tese (Doutorado em Ciências Sociais) - Instituto de Filosofia e Ciências Humanas, Universidade Estadual de Campinas, Campinas, 2016.

CARVALHO, C. P. O. O desenvolvimento da Região Nordeste nos Anos Pós-Sudene (2000-2016).

Revista Paranaense de Desenvolvimento, Curitiba, v. 39, n. 134, 2018.

COMEX. Principais produtos exportados e principais destinos dos containers de melões do Brasil. Disponível em: <http://www.mdic.gov.br/comercio-exterior/estatisticas-de-comercio-exterior/comexvis/frame-ppe?ppe=1235 $>$. Acesso em: 30 abr. 2020.

DENZIN, N. K.; LINCOLN, Y. S. Introdução: a disciplina e a prática da pesquisa qualitativa. In: DENZIN, N. K. e LINCOLN, Y. S. (Orgs.). O planejamento da pesquisa qualitativa: teorias e abordagens. 2. ed. Porto Alegre: Artmed, 2006. p. 15-41.

DIAS, A. C. A responsabilidade social das empresas viabilizado pelos incentivos fiscais com o intuito de fomentar o desenvolvimento econômico. 2011. $78 \mathrm{f}$. Monografia (Graduação em Ciências Contábeis) - Universidade de Caxias do Sul, Caxias do Sul, 2011.

FABRETTI, C. C. Contabilidade Tributária. 10ª ed. São Paulo: Atlas, 2007.

GIL, A. C. Como elaborar projetos de pesquisa. 4. ed. São Paulo: Atlas, 2007.

IBGE. Lavouras Temporárias no Rio grande do Norte. Disponível em 
$<$ https://www.ibge.gov.br/estatisticas-novoportal/economicas/agricultura-e-pecuaria/9117-producaoagricola-municipal-culturas-temporarias-e-permanentes.html?=\&t=resultados $>$. Acesso em: 26 mar. 2020.

IBGE. Produção agrícola lavoura temporária no Rio Grande do Norte. Disponível em: <https://cidades.ibge.gov.br/brasil/rn/pesquisa/14/10193>. Acesso em: 24 abr. 2020.

IBGE. Variável área plantada ou destinada a colheita 2017(hectares). Disponível em:

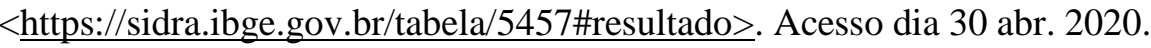

LEITE, S. A.; CASTELlANI, M. A.; RIBEIRO, A. E.; MOREIRA, A. A.; AGUIAR, W. M. M. A. Perfil dos fruticultores e diagnóstico do uso de agrotóxicos no polo de fruticultura de Livramento de Nossa Senhora, Bahia. Extensão Rural, Santa Maria, v. 23, n. 2, abr./jun. 2016.

LOCATEL, C. D.; LIMA. F. L. S. Territórios Rurais e reestruturação produtiva do capital no Rio Grande do Norte. Revista Formação, v. 1, n. 23, 2016.

LONDERO, N. Planejamento tributário como ferramenta de estratégia competitiva para micros e pequenas empresas. 2015. 30 f. Monografia (Graduação em Ciências Contábeis) - Centro de Ciências Sociais e Humanas, Universidade Federal de Santa Maria, Santa Maria, 2015.

NEVES, M. SUDENE de volta à era do Ouro? [19 de outubro de 2017]. Revista Nordeste. Disponível em: <https://revistanordeste.com.br/noticia/revista-nordeste-sudene-de-volta-era-de-ouro/>. Acesso em: 11 fev. 2020.

OLIVEIRA, L. M.; CHIEREGATO, R.; JÚNIOR, J. H. P.; GOMES, M. P. Manual de Contabilidade Tributária. $9^{a}$ ed. São Paulo: Atlas, 2010.

OLIVEIRA, A. S.; CASTELlANI, M. A.; NASCIMENTO, A. S.; MOREIRA, A. A. Perfil do sistema de produção de pinha nos polos de Fruticultura da Bahia, com ênfase nos aspectos fitossanitários da cultura. Extensão Rural, Santa Maria, v. 23, n. 2, abr./jun., 2016.

PINHEIRO, P. R. A. B. Desempenho das principais frutas exportadas pelo Rio Grande do Norte no período de 2011 a 2017. 2018. 50 f. TCC (Especialização em Gestão do Agronegócio) - Programa de Pós-Graduação em Ciências Agrárias, Universidade Federal do Paraná, Curitiba, 2018.

PORTAL DE CONTABILIDADE. Demonstração do Resultado do Exercício. Disponível em: <http://www.portaldecontabilidade.com.br/guia/demonstracaodoresultado.htm>Acesso em: 08 jul. 2020.

PRODANOV, C. C.; FREITAS, E. C. Metodologia do trabalho cientifico: metodologia e técnicas da pesquisa e do trabalho acadêmico. $2^{\circ}$ ed. Rio Grande do Sul: Universidade FEEVALE, 2013.

RECEITA FEDERAL. Carga Tributária Brasil 2017. Disponível em:

$<$ http://receita.economia.gov.br/noticias/ascom/2018/dezembro/carga-tributaria-bruta-atingiu-32-43-dopib-em-2017/carga-tributaria-2017-1.pdf >. Acesso em: 22 mar. 2020.

SALVIANO, A. M. et al. A Cultura do Melão. Embrapa. Brasília. 3 a ed. 2017

SANTOS, J. R. P.; SANTOS. J. M.; Estudo da competência da competividade das Exportações de Melão nos Estados de Rio Grande do Norte e Ceará (1997-2014). Revista Desenvolvimento Econômico. v. 20, n. 34, 2016.

SANTOS, D. N.; NESPOLO, D.; KRONHARDT, J.; SAUSEN, J.; DOMINICO, D. D.; Utilização de Incentivos Fiscais como uma ferramenta do Planejamento Tributário: o caso de uma indústria de 
embarcações localizada na Zona Franca de Manaus. In: XVII Mostra de Iniciação de Pesquisa Científica, Pós-graduação, Pesquisa e Extensão, 2017. Anais... Caxias do Sul, 2017.

SUDENE. Incentivos e benefícios fiscais e financeiros projetos beneficiados em 2018. Disponível em: $<$ http://www.sudene.gov.br/images/arquivos/incentivosfiscais/documentos/relatorio-incentivosfiscais2018.pdf $>$. Acesso em: 07 jun. 2020.

SUDENE. Manual de instrução e elaboração de pleitos de incentivos e benefícios fiscais administrados pela SUDENE. Disponível em:

$<$ http://sudene.gov.br/images/arquivos/incentivosfiscais/documentos/manual-incentivosfiscais-sudene2018.pdf>. Acesso em: 28 mai. 20120.

TEIXEIRA, E. M. O Federalismo Fiscal e as isenções do ICMS: uma análise sobre a égide da Lei Complementar no 160/2017. 2017. 56 f. Monografia (Graduação em Direito) - Universidade Católica do Salvador, Salvador, 2017.

TOLEDO, P. H. V. M. O GTDN e a SUDENE de Frutado no desenvolvimento econômico do Nordeste: Concepção e realidade. 2013. 57 f. Monografia (Graduação em Economia) - Universidade Federal do Rio de Janeiro, Rio de Janeiro, 2013.

TRIBUNA DO NORTE. A história de um Ícone do Campo. Jornal Tribuna do Norte, Natal-RN, 27 de março de 2011. Disponível em: 〈http://www.tribunadonorte.com.br/noticia/a-historia-de-um-icone-docampo/176709>. Acesso em: 26 mar. 2020.

TRIBUNA DO NORTE. Gargalos vão de logística a falta de incentivos. Jornal Tribuna do Norte, Natal-RN, 27 de outubro de 2015. Disponível em:

<http://www.tribunadonorte.com.br/noticia/gargalos-va-o-de-loga-stica-a-falta-de-incentivos-norn/325515>. Acesso em: 24 abr. 2020.

TRIBUNA DO NORTE. Produção agrícola do RN aumenta 11,5\% 2017 em relação a 2018. Jornal Tribuna do Norte, Natal-RN, 13 de outubro de 2018. Disponível em:

<http://www.tribunadonorte.com.br/noticia/ibge-produa-a-o-agra-cola-do-rn-aumentou-11-5-em-2017em-relaa-a-o-a-2016/424071>. Acesso em: 24 abr. 2020.

ZANGIROLAMI, A. Planejamento Tributário: estudo realizado em uma empresa que atua no ramo de comercio varejista de combustíveis. 2010. 97 f. Monografia (Graduação em Ciências Contábeis) Universidade Regional do Noroeste do Estado do Rio Grande do Sul, Rio Grande do Sul, 2010. 